\title{
DEVELOPMENT OF LEARNING MATERIALS ON INDUSTRIAL CHEMISTRYLECTURE TO SUPPORT ECOPRENEURSHIP IN CHEMISTRY DEPARTMENT FMIPA UNESA
}

\author{
Dian Novita $^{* 1}$ and Siti Tjahjani ${ }^{2}$ \\ ${ }^{1,2}$ Chemistry Department, FMIPA, Universitas Negeri Surabaya \\ *diannovita@unesa.ac.id
}

\begin{abstract}
Learning materials have been developed which then conducted the study and validation to the expert lecturers and then tested to the students to find out the validity of the feasibility of learning materials in the field of Industrial Chemistry as one of the supporting subjects of Ecopreneurship in Chemistry Department. From the data obtained can be concluded that learning materials in the form of Lesson Plan, Worksheet, and Instrument Rating get very good criteria. These criteria are obtained based on theoretical feasibility and empirical feasibility. Based on these results, learning tools developed can be used as learning tools for Industrial Chemistry courses to support ecopreneurship.
\end{abstract}

Keywords: ecopreneurship, industrial chemistry, learning materials.

\section{PENDAHULUAN}

Ecopreneurship ini disusun untuk menjadi penciri pembelajaran di FMIPA UNESA dalam tindak lanjut pengembangan kurikulum KKNI dan SN Dikti serta capaian FMIPA dan Unesa sebagai Ecocampus di tahun 2015 dan 2016. Ecocampus merupakan salah satu partisipasi perguruan tinggi dalam mewujudkan kampus berwawasan lingkungan [1]. Program ini ditujukan kepada perguruan tinggi di Indonesia dan bersifat sukarela, tanpa paksaan dari pemerintah. Dengan adanya program ini diharapkan munculnya kesadaran dan kepedulian segenap warga kampus untuk menjalankan mensukseskan program ini. Kampus sebagai kumpulan kaum intelektual sudah seharusnya menjadi contoh atau panutan kepada institusi atau masyarakat lain akan pentingnya menjaga kelestarian lingkungan.

Kampus yang terdiri dari ribuan mahasiswa mengkonsumsi segala bentuk kebutuhan[2]. Diperkirakan dengan jumlah yang mencapai ribuan, sampah yang dihasilkan mulai dari sampah plastik sampai sampah kertas. Dibutuhkan sebuah program atau teknologi untuk mengatasi hal tersebut. Mulai dari penyediaan tempat sampah untuk jenis sampah organik, non organik dan radioaktif. Selain itu sebuah program daur ulang kertas juga diperlukan karena selama ini kertas bekas belum dapat dimanfaatkan secara
optimal.Selain hal-hal di atas, maka perlu dilakukan perubahan dari sumber daya yang ada di kampus tersebut. Disini diperlukan perubahan life style berhubungan dengan gaya hidup seseorang, yang dalam hal ini berhubungan dengan sikap membuang sampah, sikap kepedulian terhadap lingkungan di sekitarnya, sikap untuk selalu berhemat dalam penggunaan energi, dan sikap menghargai orang lain. Untuk merubah life style tersebut tidaklah mudah, perlu kegiatan intensif, dan memerlukan waktu yang cukup lama. Upayaupaya yang dapat dilakukan untuk merubah life style tersebut antara lain dilakukan melalui matakuliah yang menunjang ecopreneurship [3][4].

Matakuliah Kimia Industri adalah salah satu matakuliah di Jurusan Kimia yang sesuai dengan ciri Ecopreneurship. Matakuliah ini merupakan matakuliah wajib di Prodi S1 Pendidikan Kimia dan Prodi S1 Kimia. Deskripsi matakuliah Kimia Industri adalah prinsip dasar dan konsep proses kimia dalam industry meliputi industri energi dari bahan bakar minyak mentah, industri energi alternatif dari minyak biji-bijian, industri fermentasi, industri sabun dan detergen, industri kertas, industri karbon dari berbagai bahan mentah, dan industri kosmetik. Dalam penelitian ini topik yang diambil dibatasi pada bahasan materi yang dapat dimungkinkan untuk 
mahasiswa mengambil data di Laboratorium Kimia. Batasan tersebut adalah prinsip dasar dan konsep proses kimia dalam industri meliputi industri energi dari minyak biji-bijian dan cara pengolahannya, industri fermentasi termasuk tempe, kecap, yogurt dan anggur, industri sabun dan detergen, industri kertas termasuk kertas daur ulang, industri karbon dari berbagai bahan mentah, dan industri kosmetik termasuk sabun wajah, aneka krim wajah, shampoo dan pewarna kosmetik.Namun untuk menunjang Ecopreneurship dalam matakuliah Kimia Industri masih diperlukan pengembangan perangkat pembelajaran dan perlu diketahui kelayakannya sebagai perangkat pembelajaran yang berbasis Ecopreneurship.
Perangkat pembelajaran yang dikembangkan adalah Rencana Pembelajaran Semester (RPS), Lembar Kerja Mahasiswa (LKM), dan Instrumen Penilaian.

\section{METODE}

Metode penelitian yang digunakan adalah metode penelitian dan pengembangan atau Research and Development $(R \& D)$. Tahaptahap dalam metode penelitian dan pengembangan yaitu: 1) tahap studi pendahuluan, 2) tahap studi pengembangan, 3) tahap evaluasi. Rancangan penelitian pengembangan kit ini dapat dilihat pada gambar di bawah ini.

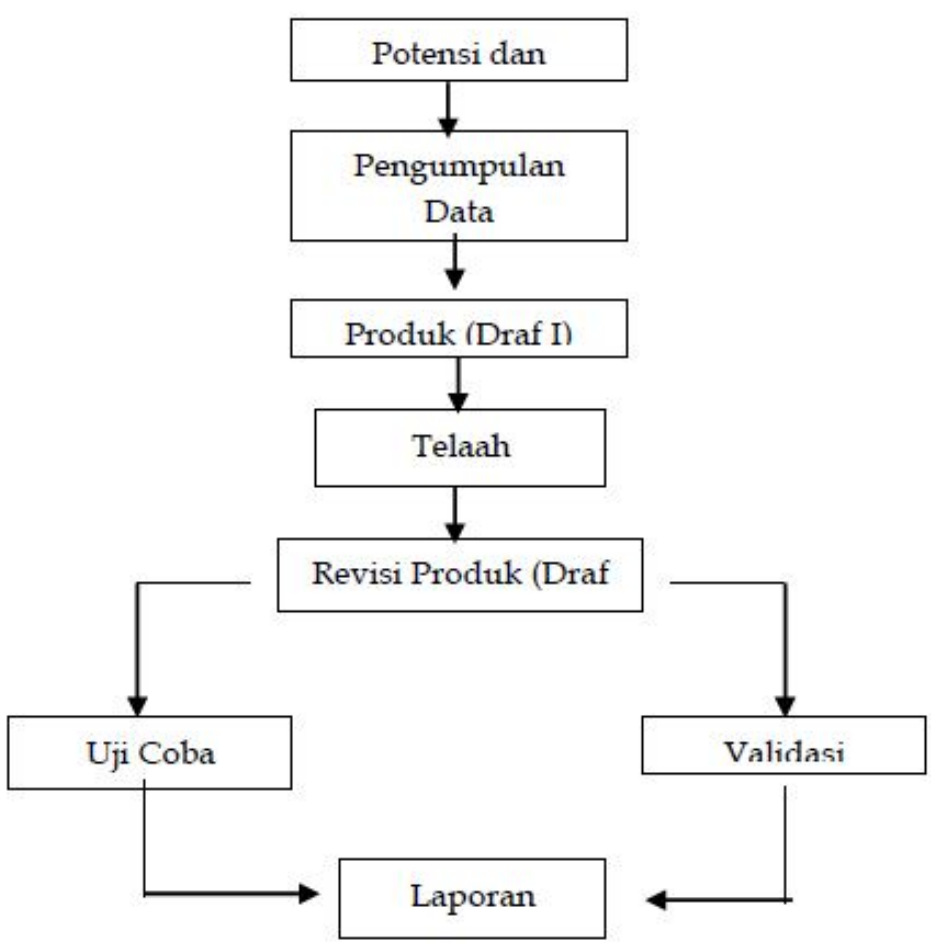

\section{Gambar 1.Tahap Kegiatan Penelitian dan Pengembangan (Research and Development/ $\boldsymbol{R} \& \boldsymbol{D})$ (Adaptasi dari Sukmadinata, 2015)}

\section{HASIL DAN PEMBAHASAN}

Perangkat pembelajaran yang dikembangkan adalah:

1. Rencana Pembelajaran Semester RPS dikembangkan sesuai dengan format yang telah ditentukan oleh universitas.

2. Lembar Kegiatan Mahasiswa

LKM dikembangkan sesuai dengan materi dalam matakuliah Kimia Industri dengan latihan pemahaman mahasiswa tentang ecopreneurship.

3. Instrumen Penilaian

Penilaian dilakukan dengan 3 hal, yaitu penilaian pemahaman ecopreneurship dalam proyek yang dikerjakan mahasiswa, penilaian proses, dan penilaian format laporan proyek mahasiswa. 
Perangkat pembelajaran ditelaah oleh dosen ahli, yaitu seorang ahli tentang materi tentang kimia Industri dan yang lainnya adalah ahli kependidikan. Dari telaah yang dilakukan memperoleh beberapa masukan. Masukannya adalah menambahkan beberapa pertanyaan di LKM tentang materi dalam Kimia Industri dan memberikan rubrik pada penilaian proses dan penilaian format laporan proyek. Perangkat pembelajaran direvisi sesuai masukan dan saran dari penelaah. Perangkat pembelajaran divalidasi oleh dosen menghasilkan data di Tabel

Tabel 1 Hasil Validasi Perangkat Pembelajaran

\begin{tabular}{|c|c|c|}
\hline No. & Aspek yang dinilai & Nilai \\
\hline \multicolumn{3}{|c|}{ Rencana Pembelajaran Semester } \\
\hline \multirow[t]{10}{*}{1} & $\begin{array}{l}\text { Capaian pembelajaran matakuliah memuat aspek sikap, pengetahuan, dan } \\
\text { keterampilan }\end{array}$ & 3,5 \\
\hline & $\begin{array}{l}\text { Kemampuan akhir yang direncanakan pada tiap tahap pembelajaran untuk } \\
\text { memenuhi capaian pembelajaran lulusan }\end{array}$ & 3,5 \\
\hline & Perumusan tujuan/indikator mendukung capaian pembelajaran & 4 \\
\hline & Bahan kajian terkait dengan kemampuan yang akan dicapai & 4 \\
\hline & Kesesuaian pemilihan strategi pembelajaran dengan indikator & 3,5 \\
\hline & Kesesuaian sumber belajar/media dengan indikator & 3,5 \\
\hline & Kesesuaian perencanaan waktu dengan materi pembelajaran & 4 \\
\hline & Kesesuaian pengalaman belajar dengan indikator & 3 \\
\hline & Butir-butir penilaian sesuai dengan indicator & 3,5 \\
\hline & Keterkinian referensi & 3 \\
\hline 2 & Kesesuaian dengan ecopreneurship & 3,5 \\
\hline 3 & Penilaian secara umum & 3,5 \\
\hline \multicolumn{3}{|c|}{ Lembar Kegiatan Makalah } \\
\hline \multirow[t]{4}{*}{1} & $\begin{array}{l}\text { Konstruksi } \\
\text { a. Sesuai dengan taraf berpikir mahasiswa. }\end{array}$ & 3.5 \\
\hline & b. Mendorong mahasiswa terlibat aktif. & 4 \\
\hline & c. Kesesuaian soal dengan tujuan dan materi. & 4 \\
\hline & d. Kesesuaian dengan ecopreneurship & 3.5 \\
\hline \multirow[t]{3}{*}{2} & $\begin{array}{l}\text { Tsi } \\
\text { a. Fenomena yang disaikan mendukung materi. }\end{array}$ & 3,5 \\
\hline & b. Kebenaran konten (fakta, konsep, prinsip, hukurn, teori dan proses ilmiah). & 3,5 \\
\hline & c. Kemutakhiran konten. & 3,5 \\
\hline \multirow[t]{3}{*}{3} & $\begin{array}{l}\text { Bahasa dan Keterbacaan } \\
\text { a. Bahasa yang dipakai sesuai dengan ysia mahasiswa. }\end{array}$ & 4 \\
\hline & b. Menggunakan bahasa Indonesia yang balk dan benar. & 4 \\
\hline & c. Istilah yang digunakan tepat dan dapat dipahami & 4 \\
\hline 4 & Penilaian secara umum & 3,5 \\
\hline \multicolumn{3}{|c|}{ Tnstrumen Penilaian } \\
\hline \multirow[t]{6}{*}{1} & a. Sesuai dengan sistematika penilaian & 3 \\
\hline & b. Kesesuaian penilaian dengan tujuan pembelajaran & 4 \\
\hline & c. Kesesuaian dengan penilaian ecopreneurship & 3,5 \\
\hline & d. Bahasa yang dipakai komunikatif & 3,5 \\
\hline & e. Menggunakan bahasa Indonesia yang bak dan benar. & 3,5 \\
\hline & f. Istilah dan skor yang digunakan tepat dan dapat dipahami & 3,5 \\
\hline 2 & Penilaian secara umum & 3,5 \\
\hline
\end{tabular}

Dari data tersebut diketahui bahwa untuk perangkat pembelajaran RPS diperoleh skor 3,58 yang menurut skala termasuk dalam kriteria sangat layak. Hal ini diperoleh karena RPS yang dikembangkan telah sesuai dengan kriteria RPS dan sesuai dengan kriteria ecopreneurship. RPS dikembangkan dengan memuat capaian pembelajaran yang memuat aspek sikap, pengetahuan, dan keterampilan. Hal ini juga sejalan dengan kriteria ecopreneurship yang terdiri dari 3 lingkup, yaitu Eco Inovation, Eco Opportunity, dan Eco Commitment [4].Eco-commitment yang merupakan kesediaan untuk berkerja keras dan memberikan tenaga serta waktu untuk perkerjaan atau aktivitas yang ramah terhadap lingkungan adalah merupakan bagian dari aspek sikap yang turut dikembangkan dalam suatu pembelajaran yang berbasis Ecopreneurship. Perumusan kemampuan akhir, tujuan/indikator, keterkaitan bahan kajian, dan perencanaan waktu mendapat skor 
yang sangat baik. Skor terendah dengan kriteria baik diperoleh dalam aspek keterkinian referensi. Referensi yang digunakan adalah referensi primer yang diperoleh tahun 1986, namun referensi kajian materi ini diperkaya dengan adanya artikel-artikel jurnal yang harus ditelaah mahasiswa sebelum melakukan perancangan proyek. Artikel-artikel jurnal ini pula yang dimasukkan pula dalam perangkat pembelajaran LKM.

Dari data tersebut juga diketahui bahwa untuk perangkat pembelajaran LKM diperoleh skor 3,55 yang menurut skala termasuk dalam kriteria sangat layak. Hal ini diperoleh karena LKM yang dikembangkan telah sesuai dengan kriteria konstruksi, isi, dan kebahasaan/keterbacaan.

Pada kriteria konstruksi diperoleh skor yang sangat baik, karena LKM yang dikembangkan telah sesuai dengan taraf berpikir mahasiswa, membuat aktif, sesuai dengan tujuan serta materi, dan sesuai dengan ecopreneurship. Dalam aspek isi yang terdiri dari fenomena yang mendukung materi, kebenaran, dan kemutakhiran konten juga memperoleh skor yang sangat baik. Hal ini karena di dalam LKM mahasiswa diberikan fenomena nyata dalam bentuk hasil penelitian yang telah diunggah sebagai artikel jurnal. Dengan menggunakan artikel jurnal mahasiswa diminta untuk menelaah fenomena dan data yang ada dan disesuaikan dengan teori yang telah mereka peroleh. Mahasiswa diminta membandingkan dan juga membuat alur prosedur yang dapat lebih lanjut mereka kembangkan dalam proyek di akhir pembelajaran.

Menurut Kainrath Pendidikan Ecopreneurshipadalah untuk membantu peserta didik menyadari pendidikan wirausaha yang ramah lingkungan, dapat diterapkan dalam kehidupan sehari-hari serta dapat memupuk rasa kemasyarakatan [5]. Suatu pembelajaran berbasis proyek berorientasi ecopreneurship dapat dilakukan agar mahasiswa dalam proses pembelajaran disamping memperoleh materi ajar juga membuat pengalaman belajar yang menarik dan bermakna sehingga berdampak pada kematangan mental, sikap, dan keterampilan peserta didik memasuki dunia kerja. Diharapkan pula mahasiswa dapat mengenali dampak teknologi dalam kehidupan sosial mereka serta dapat mengetahui interaksi antara sosial, teknologi, masyarakat dan lingkungan. ${ }^{[6]}$ Mahasiswa nantinya diharapkan dapat memahami serta menerapkan jiwa ecopreneurship sehingga nantinya mereka dapat hidup dan bekerja, serta mampu membuat keputusan yang tepat dan dapat melakukan tindakan pribadi dan sosial yang bertanggung jawab dalam masyarakat.

Hasil tertinggi diperoleh dalam aspek Bahasa/keterbacaan. Hal ini karena LKM yang dikembangkan dibuat dalam bahasa yang sesuai dan menggunakan istilah yang tepat.

Dari data Tabel 1 diketahui bahwa untuk perangkat pembelajaran RPS diperoleh skor 3,50 yang menurut skala termasuk dalam kriteria sangat layak. Hal ini diperoleh karena instrumen yang dikembangkan telah sesuai dengan sistematika penilaian, kesesuaian dengan tujuan pembelajaran dan ecopreneurship, bahasa yang baik dan komunikatif, serta istilah dan skor yang tepat dan dapat dipahami. Hal ini diperoleh karena penilaian yang dikembangkan telah mencakup 3 hal penilaian yang diperlukan, yaitu penilaian pemahaman ecopreneurship dalam proyek yang dikerjakan mahasiswa, penilaian proses, dan penilaian format laporan proyek mahasiswa. Ketiga penilaian ini telah dikembangkan untuk membantu mengetahui keterlaksanaan pembelajaran berbasis ecopreneurship yang telah dilakukan.

Salah satu upaya dalam ecopreneurship adalah meningkatkan penguasaan dan kompetensi mahasiswa dalam hal berpikir kritis, berpikir kreatif, kerja sama, dan kompetensi menghasilkan produk otentik yang berorientasi ramah lingkungan. Pemilihan dan penerapan model pembelajaran perlu pertimbangan yang cermat. Pentingnya peningkatkan kualitas proses dan hasil belajar, baik untuk menguasai pengetahuan deklaratif maupun prosedural yang nantinya akan berorientasi produk yang berorientasi ramah lingkungan adalah dengan menerapkan pembelajaran berorientasi ecopreneurship dan bermotivasi perbedaan.

Menurut Hamzah B. Uno dalam Sukoco,motivasi merupakan perbedaan antara dapat melaksanakan dan mau melaksanakan [7]. Namun motivasi lebih dekat pada mau melaksanakan tugas untuk mencapai tujuan. Motivasi adalah kekuatan, baik dari dalam maupun dari luar yang mendorong sesorang untuk mencapai tujuan tertentu yang telah 
ditetapkan sebelumnya". Menurut Jamaris dalam Saerozi dalam kaitannya dengan belajar, motivasi merupakan daya penggerak untuk melakukan kegiatan belajar[8], Individu yang memiliki motivasi yang tinggi dalam belajarnya akan berusaha melaksanakan kegiatan belajar tersebut dengan senang hati dan selalu bergairah untuk terus belajar sehingga proses belajar akan berlangsung lebih efektif dan efisien. Motivasi belajar yang tinggi tercermin dari ketekunan yang tidak mudah patah semangat untuk mencapai sukses meskipun dihadang oleh berbagai kesulitan. Motivasi yang tinggi dapat meningkatkan aktivitas belajar mahasiswa. Menurut Sudjana Hasil belajar atau achievement merupakan realisasi atau pemekaran dari kecakapan kecakapan potensial yang dimiliki oleh seseorang [9].

Penguasaan hasil belajar oleh seseorang dapat dilihat dari perilakunya, baik perilaku dalam bentuk penguasaan pengetahuan, keterampilan berpikir maupun keterampilan motorik. Kelayakan empiris mahasiswa diperoleh dari nilai skor ecopreneurship mahasiswa yang dinilai dengan menggunakan lembar tes. Lembar tes disesuaikan dengan 3 lingkup ecopreneurship, yaitu Eco Inovation, Eco Opportunity, dan Eco Commitment. Penilaian ini dilakukan oleh dosen pembimbing dan dosen penguji proyek mahasiswa.

\section{SIMPULAN DAN SARAN}

Didapatkan data bahwa perangkat pembelajaran berbasis ecopreneurship memiliki rentang nilai 3-4 sehingga dinyatakan sangat layak digunakan dalam proses pembelajaran.
Saran yang diperoleh adalah perlu adanya penilaian tentang kriteria ecopreneurship yang lebih dikembangkan lagi dan disesuaikan dengan kondisi yang ada di jurusan.

\section{DAFTAR PUSTAKA}

[1] Dunn, William N. (2003).Analisis Kebijakan Publik. Gadjah Mada University Press. Yogyakarta.

[2] Prasetyantoko.(2008).Corporate Governance Pendekatan Institusional. Jakarta: PT Gramedia Pustaka Utama.

[3] Hisrich.(2008).Kewirausahaan. New York: McGraw-Hill, Penerbit Salemba Empat.

[4] Wijatno, Serian.(2009).Pengantar Entrepreneurship. PT Gramedia, Jakarta.

[5] Kainrath, D. (2010). Ecopreneurshipin Theory and Practice. Thesis. Umea School of Business

[6] Suryana.(2003).Kewirausahaan. Salemba Empat, Jakarta.

[7] Sukoco, Iwan dan Muhyi, Herwan Abdul.(2015). Ecopreneurship dalam Menumbuhkan Usaha Berwawasan Lingkungan pada Sentra Industri Penyamakan Kulit Sukaregang Kabupaten Garut. Sosiohumaniora, Volume 17 No. 2 Juli 2015: 156- 165

[8] Saerozi, Hadromi, dan Khumaedi.(2017). Pengaruh Model Pembelajaran Proyek dan Motivasi terhadap Kompetensi Praktik Pengelasan, Journal of Vocational and Career Education, JVCE 2 (1) (2017)

[9] Sudjana, N. 2009. Dasar Dasar Proses Belajar Mengajar. Bandung: Sinar Baru 